\title{
Research on Informational Teaching Mode Under Mobile Internet Background
}

\author{
QiYanhua ${ }^{1, a}$, ChenJing ${ }^{2, b}$ \\ ${ }^{1}$ Wuhan University of Engineering Science, JiangXia District, WuHan city, Hubei Province China \\ ${ }^{2}$ Wuhan University of Engineering Science, JiangXia District, WuHan city, Hubei Province China \\ a 38684132@qq.com, ${ }^{\text {b247649248@qqq.com }}$
}

Keywords: Informational Teaching, Internet Teaching Platform, Internet

\begin{abstract}
Development and integration of mobile communications technology and computer technology, and promote the process of human society, but also accelerated the pace of information technology in education. Mobile Learning as a new form of distance education, with the wireless communication technology and mobile computing technology is widely used in education has been rapid development, so that distance education has been substantial leap. Information teaching as a guide, information technology support, application of modern teaching methods based on modern teaching philosophy. The use of mobile learning platform for learners will play a greater role on the development of education also play a better role in promoting, but also to create learning community can learn a way of learning. Fully convinced that the popularity of mobile learning only is a matter of time, in the near future it will become the information society to educate people to learn a universal way of learning.
\end{abstract}

\section{Theoretical Introduction of Information Technology}

Information technology teaching model is built on the basis of constructivist theory, their learning environment contains scenarios, collaboration, conversation and meaning construction of four elements. Information technology teaching mode can be described as: a student-centered, learners and other teachers to create situations, collaboration and conversation learning environment full play to their initiative and enthusiasm of current knowledge by carrying on Meaning Construction and use what they have learned solve practical problems.

Information is a process, and its development depends on three factors: First, people on their business activities to deepen understanding, involves the design innovation, process improvement, quality management, cost control, scientific management, risk analysis, decision optimization and other fields; second is the development of information technology related to computing, graphics technology, automation technology, digital technology, network technology, artificial intelligence and other fields; third is the permeability of the IT operational activities, the ability to transform and empowerment, involving many technical systems, such as computer-aided design, computer aided manufacturing, computer-aided process planning, enterprise resource planning, customer relationship management, supply chain management, e-commerce and industry with professional or expert system mathematical model control computers ${ }^{[1]}$.

In teaching, the teachers imparting knowledge, by instilling into students who take the initiative to get help information, facilitator; students from the passive recipients of external stimuli, and the inculcation of knowledge objects into the main body of information processing, knowledge of the significance of the initiative builders, information is no longer carried the knowledge of teachers to teach the content, but students actively construct the meaning of the object; the teaching process by the process described to explain the transition through the creation of scenarios, problem exploration, learning consultation, etc. meaning Construction of student process of the subject; also by the role of the media as a tool for teachers to explain the demonstration into active learning, collaborative exploration, construction of meaning, cognitive tools to solve practical problems. 


\section{The Internet Teaching Platform}

Learning platform via the Internet, learners can view various types of quality teaching resources, teachers can learners learning process, the number of online, long effective monitoring at logon, administrators can teaching activities Primary School to regulate guidance and better optimization classroom, so as to enhance the overall level. Although the Internet learning platform is more mature application platform, but its ongoing maintenance and functional expansion is still a top priority. Internet-based learning platform as the base camp, the platform, still needs to make further efforts in terms of cross-platform compatibility ${ }^{[2]}$. Fig. 1 shows the Internet teaching platform.

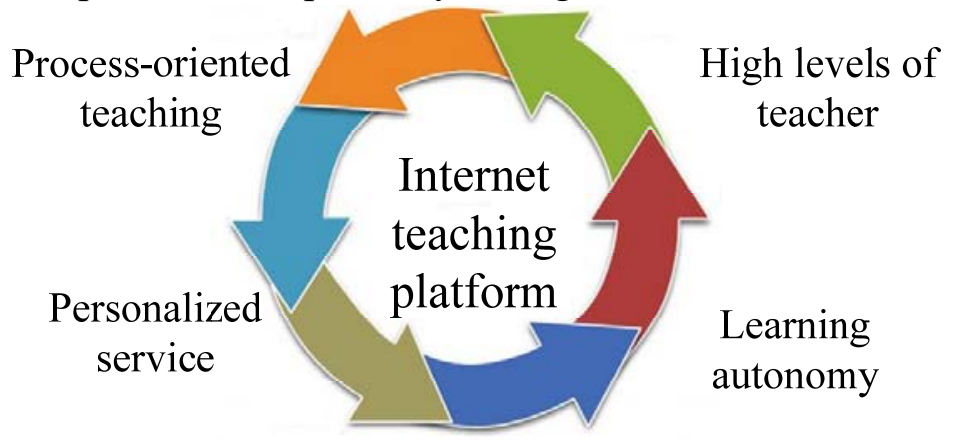

Fig. 1.The Internet teaching platform

Instructional design streamlined. Teaching process design according to the characteristics of each course, the teaching process need modular, each module teaching activities require concrete. Each module can only enter after learning tasks to complete the next learning module, in order to achieve the purpose to enhance learning. Through the process of instructional design, the learner can complete each course in accordance with the requirements step by step. Because of individual differences in the level of knowledge of learners, different learning requirements of learners, acceptance and achievable goals are different. To form a variety of hierarchical menus to learners alternative course guidelines, including an overview of the course, objectives, content, assessment plan, implementation of the recommendations, etc., in order to meet the individual and diverse teaching management. In addition, the platform can be developed for learners personalized content for learners' learning behavior data mining, to distinguish patterns of behavior of learners, learning preferences.

Independent learning learners, through the process of teaching, order management, individualized services and other measures to address the students' self-directed learning, self-monitoring, self-evaluation and other issues. Teaching management platform can also help learners to form correct self-learning method. Learners can be customized personalized service and subscribe to your attention the content according to their actual situation, truly autonomous learning. Distance education is a higher, more stringent requirement for teachers. Distance education teachers should not only have deep expertise, a broad range of scientific and cultural knowledge, but also has to help learners to self-monitoring and self-evaluation capabilities. Open University should be the selection, training a large number of outstanding teachers, enhance the core competitiveness of the school, which is also essential for teaching management ${ }^{[3]}$.

\section{The Implementation of Arts Teaching Methods}

The virtualized data center architecture, the distinguishing feature is that all the physical equipment and lines are redundant as possible. Physical server connected to the network is dual-link, the connection with storage cabinets are also dual link; all virtual servers are running on a unified resource pool consisting of multiple physical servers, after any one physical server goes down, related virtual server can automatically migrate to other normal physical server ${ }^{[5]}$. Fig.2 shows the topologies of schools virtualized data center. 


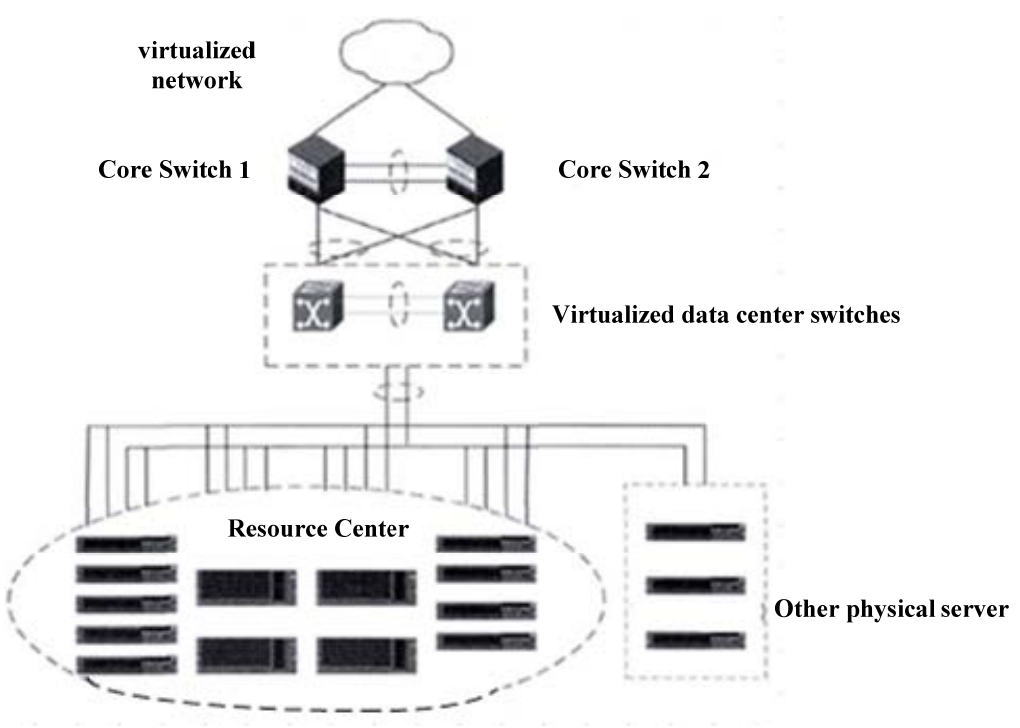

Fig. 2.The topologies of schools virtualized data center

The basic contents of the arts curriculum are as follows: Arts appreciation is an important part of the high school Arts teaching is an important way to cultivate students' ability to feel the arts and aesthetic ability. Students have a good ability to appreciate arts, enrich their emotional, strive to improve literacy, promote health, improve the formation of personality has important significance. Singing is a very practical learning content, but also the most easily accepted and happy student performances participation. Open singing course, reflects the continuity of the primary and secondary schools of arts teaching. Singing helps develop students' skills, develop students' interest in the song singing hobby, more conducive to students' performance to explore the potential and creative potential.

Instrumental arts to stimulate students' interest in learning, improve understanding of arts, expression and creativity has a very important role. Instrumental arts appreciation teaching content and teaching, singing, writing and so closely, is an effective way to train arts performance ability and aesthetic ability. Learning instrumental, not only to master twelve instruments playing skills, but to play arts instrument through and establish a good aesthetic taste, experience the euphoria of cooperation with others. This is a traditional arts education in primary and secondary schools that are not new elective series, as innovative talent has a special significance.

Arts and dance is intimate sister arts, the creation of a series of courses in arts, reflecting the trend of comprehensive art education. Students can get to know both the art of dance through arts, but also can enhance the interest in learning the art of dance through the course, experience the beauty of the art of dance. Elective opened for students learning numerous contacts and comprehensive art genre offers the opportunity of a strong arts patterns and historical drama and drama, stylish, modern movies and television arts at once with some strong main content. It will effectively broaden their artistic visions that they become integrated in order to showcase the art of the stage.

\section{The Key Technology Applications}

With the application of information technology in education presents new features: multimedia materials; global resources; individualized instruction; learning autonomy; co-operative activities; management automation; virtualized environment. Tracking emerging new technologies, and timely use of advanced technology development learning system, can improve the technical level of the system. Learning network based on mobile Internet technology platform. By leveraging mobile learning means learning network platform diversification, new forms of learning, learning time fragmentation, place of study of the advantages of flow, further transform the building mobile learning network platform. Learners through mobile learning network platform, using a mobile phone terminal device or tablet, anytime, anywhere, independently complete the learning activities. 
The rapid development of intelligent terminal products, wireless mobile applications in large numbers, the desktop era to the era of mobile digital learning show more moved, e-readers, the era of mobile Internet has come. Applications appear on the network infrastructure, namely, the achievement desktop computers, notebook computers, smart terminals simultaneously access needs. Since the establishment of the cloud computing model, after entering the PC era, people of specific equipment, terminal equipment decreased attention. Compared with the traditional technical route, through the deployment of virtualization cloud computing service model, can provide a more flexible framework for secure IT resource pool, reducing the threshold of economic development of various applications, students are easy and economical sharing of information infrastructure.

Virtual reality, the use of computer technology, multimedia integration of 3D graphics technology, simulation produces three-dimensional space, the visual, auditory, tactile immersive simulation of reality of things. Programs and code, resources and services in the cloud, hardware environment, computing resources in the form of container in the cloud, just call can be used. Data glove helmet scene simulation data showing knowledge, learning and training. Such as technology, team members can be used in complete cooperation to complete the job; technology, knowledge can be a topic for organizational resources, not learning community members sharing.

\section{Conclusions}

Art teaching not exist in isolation, and it is difficult to let go with the other courses of contact. Arts learning can't be a single, teaching mode is rich and comprehensive. Students receive education on ways and means to directly influence their understanding and sensibility, but also on the development of learning abilities has inspired effect on other aspects of literacy beyond the artistic disciplines have to enhance the role. Mobile learning to deliver information via wireless communication technology teaching, so that students can learn a new way of learning at any time. Mobile communication and education by moving the effective integration of education, the role of education in contemporary plays will be increasing. Art curriculum standards repeatedly referred to disciplinary, its purpose is to further broaden their fields of study, enrich students knowledge, students multiple perspectives, divergent thinking, cultivate students' comprehensive quality.

\section{References}

[1] Toby J V, Anthony T V. Green IT-Reduce Your Information System's Environmental Impact While Adding to the Bottom Line [M]. New York: McGraw-Hill Osborne Media, 2008.

[2] Jha AK, DesRoches C M, Campbell E G, et al. Use of electronic health records in US schools [J]. New England Journal of Medicine, 2009, 360(16): 1628-1638.

[3] Hwang, G.J.\& Tsai, C.C. Research Trends in Mobile and Ubiquitous Learning: A Review of Publications in Selected Journals from 2001 to 2010 [J].British Journal of Educational Technology,(4):65-70.(2011).

[4] Keskin,N.O.\&Metcalf,D. The Current Perspectives, Theories and Practices of Mobile Learning [J].The Turkish Online Journal of Educational Technology, 2011 (2):202-20.

[5] Wong,L.H. \& Looi,C.-K. What Seams Do We Remove in Mobile-Assisted Seamless Learning, A Critical Review of the Literature [J]. Computers \&Education, 2011 (4):2364-2381. 